\title{
Influence of an exercise program on cardiac remodeling and functional capacity in patients with stroke (CRONuS trial): study protocol for a randomized controlled trial
}

Josiela Cristina da Silva Rodrigues ${ }^{1}$, Gustavo José Luvizutto², Rafael Dalle Molle da Costa', Robson Aparecido Prudente', Taís Regina da Silva', Juli Thomaz de Souza4,

Caroline Ferreira da Silva Mazeto Pupo da Silveira ${ }^{4}$, Daniele Andreza Antonelli Rossi ${ }^{4}$, Fernanda Cristina Winckler ${ }^{3}$, Gabriel Pinheiro Modolo ${ }^{3}$, Tainá Fabri Carneiro Valadão ${ }^{4}$, Letícia Cláudia de Oliveira Antunes ${ }^{1}$,

Luis Cuadrado Martin ${ }^{4}$, Rodrigo Bazan ${ }^{3}$ and Silméia Garcia Zanati Bazan ${ }^{4^{*}}$ (D)

\begin{abstract}
Background: Cardiovascular rehabilitation is one of the treatment options for post-stroke individuals in order to improve functional independence in activities of daily life and reduce energy expenditure. The aim of this trial is to evaluate the effect of an exercise program on the echocardiographic variables, functional capacity, inflammatory response, neurological status, nutritional status, cardiologic evaluation, and quality of life of patients after stroke.

Methods/design: This is a randomized controlled trial including patients with ischemic stroke in the chronic phase. The patients will be evaluated at the beginning of the study and after 16 weeks. This will include clinical and physical evaluation, 6-min walk test, neurological assessment, nutritional assessment, ambulatory blood pressure monitoring, transthoracic echocardiography, and assessment of the quality of life. The sample size has been determined as 40 patients, who will be divided into two groups: control group (CG; $n=20)$ and intervention group (IG; $n=20$ ). The CG will undergo conventional physiotherapy for 45 min, three times a week, up to 16 weeks, while the IG will be put on a cardiovascular rehabilitation program consisting of heating, aerobic exercise, and muscle strengthening for 45 min, three times a week, for 16 weeks. The primary endpoint will be functional capacity following a 6-min walk test (delta $\mathrm{max}_{\mathrm{VO}}$ ) and morphofunctional echocardiographic variables (indexed left ventricular mass) before and after the intervention.
\end{abstract}

Discussion: We expect to observe an improvement in cardiac structural and functional abnormalities in the IG, on echocardiography and biochemical examination, and that the improvement of these parameters after cardiovascular rehabilitation will have a favorable impact on the functional capacity and quality of life of patients after stroke.

Trial registration: REBEC, RBR-4wk4b3. Registered on 19 September 2016.

Keywords: Stroke, Physical exercise, Cardiovascular rehabilitation, Echocardiography, Functional capacity

\footnotetext{
* Correspondence: sgzanati@fmb.unesp.br

${ }^{4}$ Department of Internal Medicine, Botucatu Medical School (UNESP), São

Paulo State University, District of Rubião Junior, Botucatu, SP 18618-687,

Brazil

Full list of author information is available at the end of the article
}

(c) The Author(s). 2019 Open Access This article is distributed under the terms of the Creative Commons Attribution 4.0 International License (http://creativecommons.org/licenses/by/4.0/), which permits unrestricted use, distribution, and reproduction in any medium, provided you give appropriate credit to the original author(s) and the source, provide a link to the Creative Commons license, and indicate if changes were made. The Creative Commons Public Domain Dedication waiver (http://creativecommons.org/publicdomain/zero/1.0/) applies to the data made available in this article, unless otherwise stated. 


\section{Background}

Worldwide, stroke is a leading cause of morbidity and mortality, affecting around 200,000 individuals annually. In addition, it is a major cause of chronic disability in adults, with major impacts on the health and quality of life of the affected population [1,2].

Stroke is defined as an episode of sudden neurological dysfunction of ischemic or hemorrhagic origin, with persistent clinical symptoms over an hour and evidence of demonstrable lesion on imaging tests [3]. Pathologically, stroke can be defined as brain cell death resulting from a prolonged ischemic event [4].

The incidence of stroke is greater in men aged 45-85 years and in women over 85 years. The major risk factors for ischemic stroke are increased blood pressure, diabetes mellitus (DM), cardiac arrhythmias, dyslipidemia, smoking, physical inactivity, genetic or family history of stroke, chronic kidney disease, and sleep apnea syndrome [5]. The etiology of hemorrhagic stroke can be primary (hypertension or amyloid angiopathy) or secondary to vascular malformations, such as aneurysm, cavernous angioma, venous angioma, venous sinus thrombosis, vasculopathies, and central nervous system tumors, among others [6].

After a stroke, individuals require long periods of rehabilitation to increase their functional capacity and to minimize the sequelae resulting from brain injury $[7,8]$. In the chronic phase of stroke, $62 \%$ of patients need assistance in activities of daily living (ADL), and less than half of patients are able to perform independent walking, which is the most disabling outcome of the disease, decreasing their overall physical capacity [9-11].

Inactivity through reduced mobility and low levels of aerobic capacity after stroke result in several dysfunctions, such as reduction in cardiorespiratory fitness, loss of $20 \%$ of the cross-sectional area of the muscle, and an increase of about $25 \%$ of intramuscular fat, leading to osteoporosis. There is also the circulatory involvement of the lower extremities, as well as psychological effects such as apathy and depression [8-12]. In association with other comorbidities such as DM, hypertension, and increased body mass index, the risk of associated cardiovascular events may increase in addition to recurrence of stroke [13].

In conventional rehabilitation after stroke, the goal is to achieve maximum functional recovery $[14,15]$. However, approximately $75 \%$ of individuals have associated heart disease after experiencing a stroke, thereby reducing their functional capacity to perform ADL [16-18]. Immobility after stroke results in resistance to physical exercise, including ADL $[19,20]$.

Several studies have reported that the maximum oxygen capacity $\left(\mathrm{VO}_{2 \max }\right)$, defined as the critical (peak) oxygen capacity during aerobic activity, is reduced to $10-17 \mathrm{ml} / \mathrm{kg} / \mathrm{min}$ in the first 30 days after stroke, and does not reach values $>20 \mathrm{ml} / \mathrm{kg} / \mathrm{min}$ after 6 months of the event [21-26]. $\mathrm{VO}_{2 \max }$ values after stroke decrease by $25-45 \%$ compared to healthy individuals in the same age group, which may interfere with the rehabilitation process and functional prognosis in the long term [27, 28].

Therefore, cardiorespiratory rehabilitation aims to provide greater functional independence during ADL with lower energy expenditure [28]. Several authors have reported that conventional rehabilitation is effective in improving the functional independence of individuals after stroke, but cardiorespiratory rehabilitation can restore aerobic capacity, reduce energy expenditure to perform ADL, and reduce the occurrence of cardiac events and recurrence of stroke [14, 15, 19, 20, 26-28]. However, the type, frequency, and appropriate method to achieve these goals during cardiorespiratory rehabilitation remain unclear in the literature. Hence, this study has clinical importance.

The main aim of this study is to evaluate the effect of a cardiovascular rehabilitation program on morphofunctional echocardiographic variables and functional capacity in patients with chronic ischemic stroke. In addition, we will assess the effects of cardiovascular rehabilitation on the inflammatory response, neurological status, nutritional status, cardiologic evaluation, and quality of life. We also aim to evaluate the association between clinical variables (age, anthropometric data, mean systolic blood pressure, 24-h diastolic blood pressure, magnitude of the nocturnal decrease in systolic blood pressure, diastolic and pulse pressure, use of antihypertensive medications) and echocardiographic variables and $\mathrm{VO}_{2 \max }$.

\section{Methods/design \\ Design}

This single-center, randomized, single-blind, parallel group study of 40 patients with stroke will be conducted in accordance with the Consolidated Standards of Reporting Trials (CONSORT) 2010. A flow diagram of the study is presented in Fig. 1.

\section{Patient population}

Participants were recruited from the Cardiac RemOdeliNg and functional capacity in patients with Stroke (CRONuS) trial, a single-center, randomized, single-blinded study of cardiac rehabilitation in 40 individuals with stroke at UNESP - University Estadual Paulista, Botucatu Medical School, Brazil.

\section{Inclusion criteria}

Participants older than 18 years of either sex, with a history of ischemic stroke, modified Rankin scale $(\mathrm{mRS}) \leq 2$, and currently in the chronic phase of stroke (6 to 12 months after onset of symptoms), but clinically 


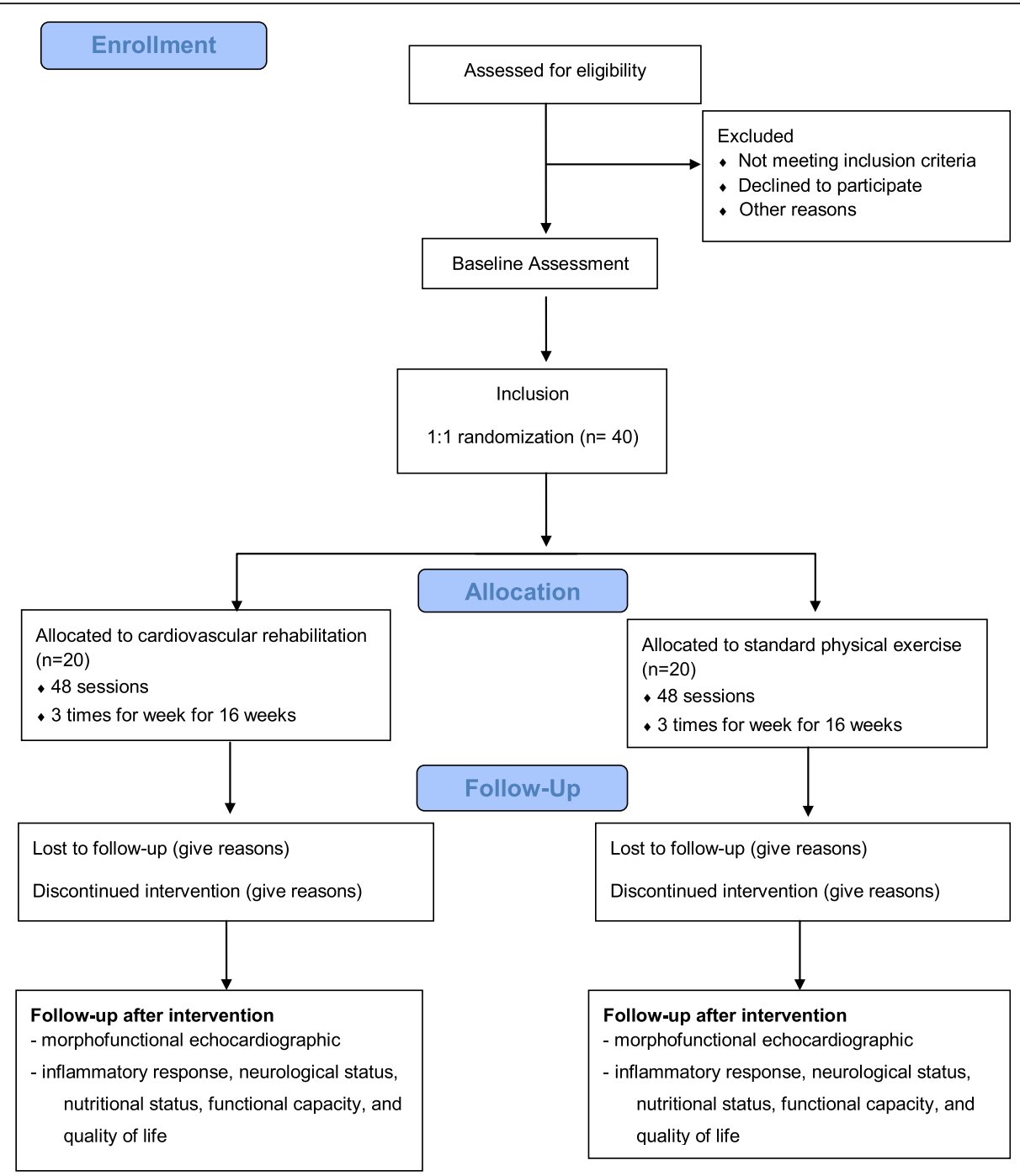

Fig. 1 Study flow diagram

stable to participate in the study after discharge from hospital [28].

\section{Exclusion criteria}

Patients with hemorrhagic stroke, $\mathrm{mRS}>2$, uncontrolled hypertension (systolic blood pressure $\geq 150 \mathrm{mmHg}$ ), history of angina in the last 3 months, uncontrolled epilepsy, persistent or permanent atrial fibrillation and/or using a pacemaker, presence of valvulopathies such as mitral and/or aortic stenosis, presence of grade IV heart failure, stage $\mathrm{D}$ chronic obstructive pulmonary disease, and life expectancy $<6$ months.

\section{Randomization and blinding}

The concealed randomization schedule will be established using a computer-generated random number sequence and maintained by an offsite investigator who will not be involved with the enrolment nor the assessment of study participants. A second research assistant will sequentially open consecutively numbered, randomly ordered, opaque envelopes containing the group allocation (in a 1:1 ratio) after baseline assessment. The patients will be evaluated before the beginning of the first session and a week after the last session by a blinded investigator.

\section{Intervention}

Frequency, duration, intensity, and supervision standards will be established for the implementation and maintenance of the cardiovascular rehabilitation program, which proposes approximately $45 \mathrm{~min}$ of exercises, three times a week, for 16 weeks (48 sessions), consisting of the following three phases [28-30]:

a) Heating: light walk for a duration of 5 to $10 \mathrm{~min}$. 
b) Aerobic exercises: 30 min of aerobic exercise on the treadmill without programmed increase in speed, compatible with walking ability of the patient, and achieving approximately 40 to $80 \%$ of maximum heart rate reserve. It is calculated by the Karvonen formula for target heart rate where Target heart rate $=[\%$ intensity $\times($ Maximum HR - Resting HR $)]$ + Resting HR; it can be readjusted according to the sessions and is progressive. This phase will take place under professional supervision.

c) Muscle cooling: static stretching of the hamstrings, quadriceps, sural triceps, and hip adductors for $5-10 \mathrm{~min}$.

The protocol will include physiologic monitoring of blood pressure, heart rate, respiratory rate, peripheral oxygen saturation, and perceived exertion (modified BORG scale). The individual will also be instructed to stop the activity if any discomfort is felt.

Patients in the control group will receive conventional outpatient physiotherapeutic care at the Clinical Hospital, UNESP-University Estadual Paulista, Botucatu Medical School, Brazil. No changes will be made to the standard hospital protocol in terms of the content, time, or duration of the session. The protocol will be based on physiotherapeutic intervention guided by the National Institute for Health and Care Excellence (2013), with exercises consisting of $10 \mathrm{~min}$ of stretching exercises for the lower limbs, $15 \mathrm{~min}$ of strengthening exercises with emphasis on core, knee extensors and flexors, plantar flexors and dorsiflexors, and 20 min of gait training with obstacles and variabile speed. Patients will wear orthoses for gait training physical therapy three times a week for 16 weeks, for 48 sessions in total.

\section{Primary outcome measures}

The primary endpoint will be measured as functional capacity following a 6-min walk test (delta $\operatorname{maxVO}_{2}$ ) and morphofunctional echocardiographic variables (indexed left ventricular mass) before and after the intervention.

\section{Secondary outcome measures}

The secondary endpoints will be inflammatory responses, neurological status, nutritional status, cardiologic evaluation, and quality of life.

\section{Adverse effects}

Adverse effects, frequency, duration, exercise intensity, and/or other relevant events will be recorded every week.

\section{Procedures (template)}

Individuals diagnosed with ischemic stroke will be sent to the rehabilitation center after discharge from the hospital. All individuals with ischemic stroke confirmed by a computed tomography $(\mathrm{CT})$ or magnetic resonance imaging (MRI) scan will be invited to participate in the study. The patient, a family member, or guardian must sign an informed consent form. The individuals will then be evaluated for their clinical and neurological status. Individuals will be assessed using the National Institutes of Health Stroke Scale (NIHSS), the Barthel Index of $\mathrm{ADL}$, and the mRS. The aerobic capacity will be evaluated by $\mathrm{VO}_{2 \max }$, functional capacity will be assessed by a 6-min walk test, nutritional status by electric bioimpedance, cardiologic examination by ecocardiography, and laboratory exams and the quality of life will be based on the European Quality of Life Scale. The tests will be performed by an investigator who is blinded to the treatment that the patient received before the first session and a week after the last session. After the clinical screening, they will be randomized into the following two groups: 1) control group (CG; 20 patients); 2) intervention group (IG; 20 patients) (Fig. 2).

\section{Data monitoring}

Patients of both groups, CG and IG, will be evaluated initially and after 16 weeks of research, using the following procedures.

\section{Clinical evaluation}

The clinical evaluation will include anamnesis and a general physical examination, recording demographics, morbidities, and medications in use.

\section{Physical assessment}

The physical evaluation will consist of anthropometric measures and evaluation of the peripheral muscular strength.

\section{Evaluation of functional capacity Aerobic capacity}

A maximum stress test will be used to obtain $\mathrm{VO}_{2 \max }$, peak work rate, and anaerobic ventilatory threshold. The heart rate and resting blood pressure will be measured before and after the exercise. The stress test will be based on a modified Bruce protocol that uses a time-dependent slope [31]. The protocol will be based on the study by Tang et al. [32], which used 5, 10, or 15 -watt work rates for a total test duration of between 8 and $10 \mathrm{~min}$.

\section{Six-minute walk test}

The 6-min walk test establishes functional fitness of gait through performance and physical resistance. The test measures the maximum distance reached along a course of $30 \mathrm{~m}$ in $6 \mathrm{~min}$. The expected distance to be reached by the patient will be calculated based on age, sex, weight, and height $[33,34]$. Equipment required for the test include a stopwatch, cones for circuit delimitation, 


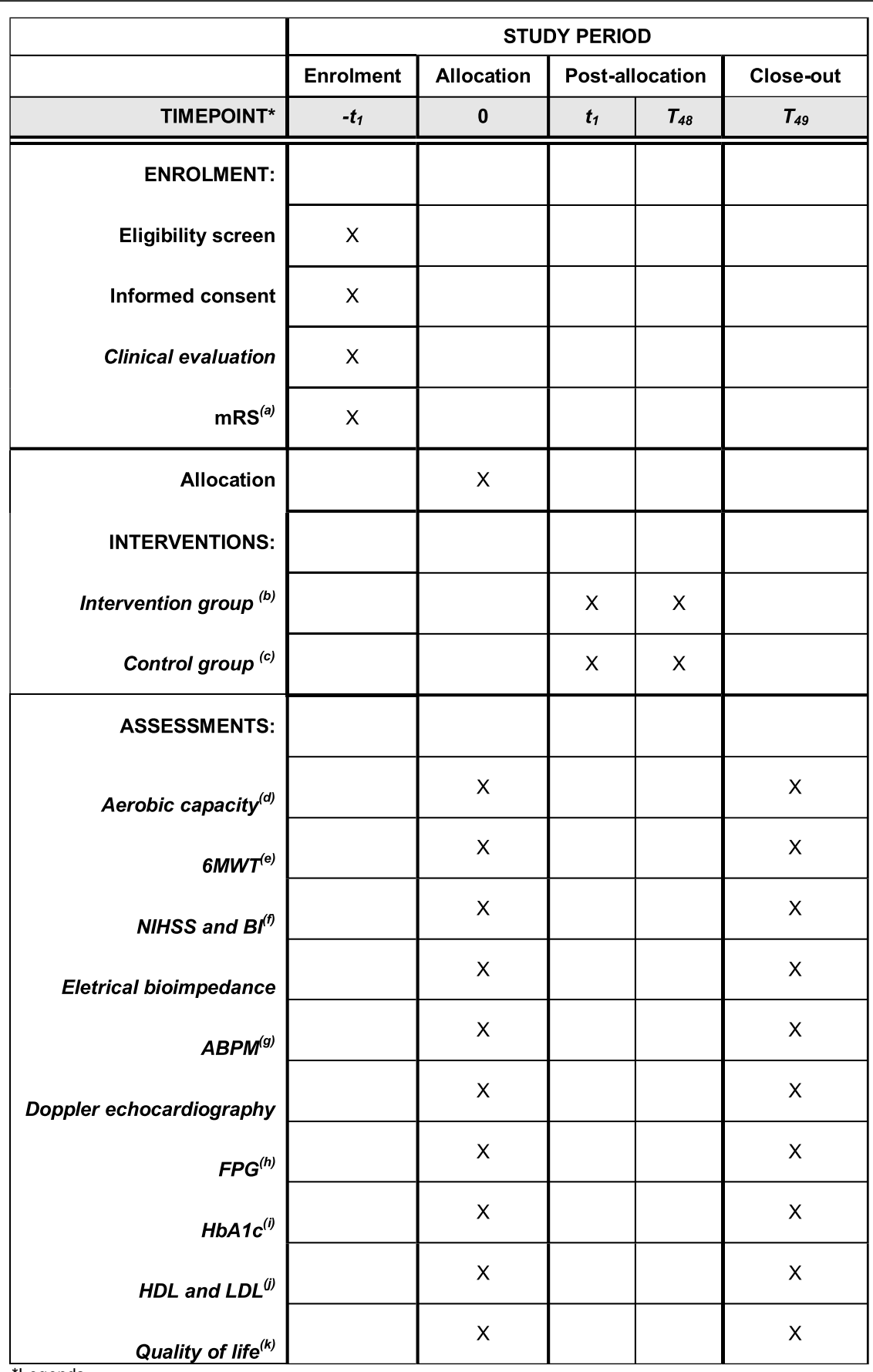

\footnotetext{
(a) Modified Rankin Scale

(b) Cardiovascular rehabilitation program

(c) Standard rehabilitation program

(d) $\mathrm{VO}_{2 \max }$

(e) 6-minute walk test

(f) National Institutes of Health Stroke Scale and Bathel Index

(g) Ambulatory blood pressure monitoring

(h) Fast plasma glucose test

(i) Glycosilated hemoglobin

(j) High and low density lipoproteins

(k) Quality of life measured by The European (5D) Quality of life Scale
}

Fig. 2 Template of recommended content for the schedule of enrolment, interventions, and assessments. 6MWT 6-min walk test, ABPM ambulatory blood pressure monitoring, BI Barthel Index, LDL low-density lipoprotein, HDL high-density lipoprotein, FPG Fast plasma glucose test, to evaluate the glycemic control 
sphygmomanometer, stethoscope, and pulse oximeter. According to the protocol proposed by the American Thoracic Society guidelines, the evaluator should not walk with the patient, but may walk behind the patient if necessary to carry the oxygen source or in case the patient loses balance. During the test, encouraging (standardized) phrases should be used over time. Vital signs are checked at the beginning and end of the test [35].

\section{Neurological and functional evaluation National Institutes of Health Stroke Scale}

The NIHSS is an assessment to quantify the neurological deficits as well as the severity of the stroke. The assessment can be performed by both medical staff and health professionals with proven training and certification [1].

\section{Modified Rankin Scale}

The mRS is to assess the degree of independence and determine if patients can care for themselves during ADL [1]. The scale ranges from 0 to 6 , and the greater the score, the lower the functional capacity.

\section{Barthel Index}

The Barthel Index will be used to measure the functional independence of individuals in $10 \mathrm{ADL}$, and the score varies from 0 to 100 . A score above 95 indicates that an individual is independent in all ADL [1].

\section{Nutritional assessment \\ Electrical bioimpedance}

Electrical bioimpedance is a non-invasive, practical, and reproducible method for evaluation of the body composition and distribution of intra- and extracellular fluids of a patient $[36,37]$. Based on the principle that different body tissues offer different resistance levels to the passage of an electric current, electrodes are placed at the tips of the thumbs, middle fingers, and heels for passing a low intensity electrical current. The amount of resistance offered helps in assessing tissue differentiation and distribution of body fat [37]. It also provides data on body mass index, which is an anthropometric indicator to establish nutritional status and measure abdominal circumference as an indicator of chronic diseases.

\section{Cardiological evaluation}

\section{Ambulatory blood pressure monitoring}

Ambulatory blood pressure monitoring is a diagnostic method that monitors 24-h changes in blood pressure, during both wakefulness and sleep, and its effect on the patient. It allows a better understanding of systemic arterial hypertension for diagnosis, prognosis, and appropriate treatment [38]. The device will be programmed for readings at 20-min intervals during wakefulness and
30 min during sleep, with a minimum of 14 readings when awake and seven during sleep. The period of vigilance will be between $7 \mathrm{am}$ and $10 \mathrm{pm}$. At least two test measures will be performed before the patient is discharged. The readings will be considered valid if there is a minimum of $24 \mathrm{~h}$ of recording and a minimum number of valid measures per hour (three during the waking hours and two during sleep). The following parameters will be analyzed: systolic mean arterial pressure, diastolic and $24 \mathrm{~h}$ pulse pressures (wakefulness and sleep), and magnitude of the nocturnal decrease in systolic, diastolic, and pulse pressures [39].

\section{Doppler echocardiographic evaluation}

The Doppler echocardiographic evaluations will be performed by a single examiner using a Vivid S6 (General Electric Medical Systems, Israel) with multi-frequency ultrasonic transducer $2.0-3.5 \mathrm{MHz}$. During the procedure, patients will remain in a left lateral decubitus position, with the left upper limb slightly flexed under the head. An electrocardiographic shunt will be continuously monitored.

The images will be obtained and analyzed following the recommendations of the American Society of Echocardiography [40, 41].

\section{Morphometric variables}

- Maximum left atrium diameter (LA, cm)

- Left atrial volume (LAV, mL), obtained by the Simpson method in two longitudinal planes, four and two chambers

- Left ventricular diastolic and systolic diameters of the left ventricle (LV, mm): LVDD and LVSD, respectively

- Interventricular septum diastolic thickness (IVSDT) and posterior wall diastolic thickness (PWDT) of the LV (mm): IVSDT and PWDT, respectively

- Relative thickness of the LV (LVRT) $=(2 \times$ PWDT $) /$ LVDD

- Left ventricular mass (LVM, g) $=0.8 \times\{1.04 \times[($ IVSDT + PWDT + LVDD) $)^{3}-$ LVDD $\left.\left.^{3}\right]\right\}+0.6$

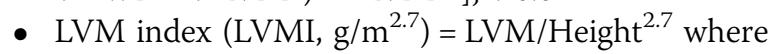
LVMI is LV mass indexed to height.

\section{Systolic function variables}

- LV ejection fraction (LVEF), obtained by the Simpson biplane method

- Percentage of variation in ventricular diameter $(\% \Delta \mathrm{D})=[\mathrm{LVDD}-\mathrm{LVSD}) / \mathrm{LVDD}] \times 100$

- Maximum systolic excursion velocity of the mitral annulus: $\mathrm{S}$ wave, obtained by spectral recording of the movement of mitral annulus, in its medial and lateral portions on tissue Doppler 


\section{Diastolic function variables}

- LAV (mL), normalized to the body surface (LAVI, $\left.\mathrm{mL} / \mathrm{m}^{2}\right)$

- Maximum early ventricular filling velocity (E wave peak, $\mathrm{cm} / \mathrm{s}$ ): obtained by spectral Doppler recording of the transmitral diastolic flow

- Maximum late filling velocity during atrial contraction (A wave peak, $\mathrm{cm} / \mathrm{s}$ ): obtained by spectral Doppler recording of the transmitral diastolic flow

- E/A ratio

- Isovolumetric relaxation time of the LV (ms), corresponding to the period between the end of the ventricular ejection and the beginning of mitral transvalvular diastolic flow

- E-wave deceleration time (ms) corresponding to the time between the initial velocity peak of the mitral transvalvular flow and its extrapolation to the baseline

- Maximum excursion velocities of the mitral annulus, in the early ventricular filling phase (E' medium, $\mathrm{cm} / \mathrm{s}$ ) and during the atrial contraction ( $\mathrm{A}^{\prime}$ medium, $\mathrm{cm} / \mathrm{s}$ ), obtained by the spectral recording of tissue Doppler of movement of the ring mitral, in its medial and lateral portions

- E/E' medium ratio

\section{Laboratory evaluation}

A) Fasting plasma glucose test: to evaluate glycemic control. It reflects the lowest plasma glucose values of the day. Possible to establish comorbidities such as type 2 DM [42]

B) Glycosylated hemoglobin: allows the monitoring of glycemic control in diabetic patients since it provides information without large fluctuations on the retrospective index of plasma glucose and is directly related to the risk of complications in patients with type 1 and 2 DM [43]

C) High density lipoproteins and low density lipoproteins

D) Pro-inflammatory cytokines: evaluate levels of inflammatory response in the body, interleukins (IL-1 $\beta$, IL-10, and IL-6), C-reactive protein, and tumor necrosis factors [44]

\section{Quality of life assessment \\ EuroQol}

The European (5D) Quality of Life Scale (EuroQol) will be used to assess the impact of stroke on an individual's quality of life through five parameters structured on mobility, personal care, usual activities, pain/discomfort, and anxiety/depression ranging from 0 to 10 . The higher the score, the worse the perception of quality of life. At the end of the test, the patient should report their health on an ordinal scale of 0 to 100, and the closer to 0 , the worse their condition, and the closer to 100 , the better $[45,46]$.

\section{Sample size estimation}

The sample size was calculated to match primary outcome with sample size estimation.

According to Framingham data [47], an increase of 20 $\mathrm{g} / \mathrm{m}^{2.7}$ in left ventricular mass index presents a hazard ratio to hard end points of about 1.5; in this study the standard deviation was $30 \mathrm{~g} / \mathrm{m}^{2.7}$. To detect these clinically significant differences between groups, with a fixed alpha error of 0.05 and beta error of $0.20,37$ patients per group will be needed.

According to the cohort of Presher et al. [48], an increase of $66 \mathrm{~m}$ in the 6-min walking test discriminates survivors from non- survivors among heart failure patients; in that study the standard deviation was $90 \mathrm{~m}$. To detect these clinically significant differences between groups, with a fixed alpha error of 0.05 and beta error of $0.20,31$ patients per group will be needed.

Therefore, we will study 40 patients per group to detect these differences properly.

\section{Statistical analysis}

Continuous variables will be expressed as means and standard deviations or medians and interquartile ranges. The associations between clinical and echocardiographic variables will be evaluated by Student's $t$-test for the variables with normal distribution, or Mann-Whitney test with non-normal distribution for comparison between groups. Comparisons between the values before and after the intervention will be made using the paired $t$-test. The associations between the continuous variables, in the same group and before and after the intervention, will be evaluated by means of repeated measures ANOVA correlation test. Data will be analyzed using SPSS version 22 (SPSS Inc., Chicago, IL, USA) and will be considered statistically significant at a $p$ value $<0.05$.

\section{Discussion}

The CRONuS trial presents clinic relevance and is necessary since studies have revealed that the conventional rehabilitation undergone by patients after stroke improves their functional independence. It is expected that cardiovascular rehabilitation will improve the structural and functional cardiac alterations-as assessed by echocardiography and the biochemical profile-of patients in the intervention group, and that the amelioration of these parameters after the cardiovascular rehabilitation will have a favorable impact on functional capacity, as shown by improvements in the 6-min walk test distance, $\mathrm{VO}_{2 \max }$, and quality of life in patients after stroke. 
Cardiac rehabilitation is a widely used protocol in older people with cardiovascular disease. While physical exercise is well accepted for secondary prevention of cardiovascular disease after stroke, it is also indicated for primary prevention. Our findings may be applicable towards improving the practice of cardiac rehabilitation of patients in the chronic phase of ischemic stroke to improve cardiovascular outcome and reduce its recurrence (Additional file 1).

\section{Trial status}

This trial is ongoing.

\section{Additional file}

Additional file 1: SPIRIT 2013 checklist: Recommended items to address in a clinical trial protocol and related documents. (DOCX $52 \mathrm{~kb}$ )

\begin{abstract}
Abbreviations
ADL: Activities of daily living; CG: Control group; DM: Diabetes mellitus; EuroQol: The European (5D) Quality of Life Scale; IG: Intervention group; IVSDT: Interventricular septum diastolic thickness; LAV: Left atrial volume; LVDD: Left ventricular diastolic diameter; LVEF: Left ventricular ejection fraction; LVM: Left ventricular mass; LVRT: Left ventricular relative thickness; LVSD: Left ventricular systolic diameter; mRS: Modified Rankin Scale; NIHSS: National Institutes of Health Stroke Scale; PWDT: Posterior wall diastolic thickness; THR: Target heart rate; $\mathrm{VO}_{2}$ max: Maximum oxygen capacity
\end{abstract}

\section{Acknowledgements}

The investigators would like to acknowledge the Clinical Hospital at Botucatu Medical School for supporting this trial.

\section{Funding}

The CRONuS trial will not have external sources of funding. This trial will be conducted with no external funding and was instead funded from researchers' own resources and support from the Clinical Hospital at Botucatu Medical School. All assessments will be conducted at the Botucatu Medical School within the Center of Rehabilitation, Botucatu, Brazil.

\section{Availability of data and materials}

Not applicable.

\section{Authors' contributions}

JCSR and SGZB were responsible for project inception. JCSR, GJL, RDMC, RAP, TRS, JTS, CFSMPS, DAAR, FW, GPM, TFCV, LCOA, RB, and SGZB were involved in study design, protocol preparation, drafting the manuscript, and acquisition of funding. LCM conceived the statistical analyses and sample size. JCSR has been involved in data merging with the principal CRONuS trial. JCSR, GJL, LCOA, RAP, TRS, and RDMC prepared cardiac rehabilitation protocol details. All authors have reviewed and approved the final manuscript of the protocol.

\section{Ethics approval and consent to participate}

This trial was approved by a Committee for Ethics in Research involving human subjects from Botucatu Medical School (CAAE 56888416.2.0000.5411). On inclusion, all subjects will be asked for their written informed consent to participate in accordance with the Declaration of Helsinki II.

\section{Competing interests}

The authors declare that they have no competing interests.

\section{Publisher's Note}

Springer Nature remains neutral with regard to jurisdictional claims in published maps and institutional affiliations.

\section{Author details}

'Department of Rehabilitation, Botucatu Medical School (UNESP), São Paulo State University, São Paulo, Brazil. ${ }^{2}$ Department of Applied Physiotherapy, Triangulo Mineiro Federal University, Uberaba, Brazil. ${ }^{3}$ Department of Neurology, Psychology and Psychiatry, Botucatu Medical School (UNESP), São Paulo State University, São Paulo, Brazil. ${ }^{4}$ Department of Internal Medicine, Botucatu Medical School (UNESP), São Paulo State University, District of Rubião Junior, Botucatu, SP 18618-687, Brazil.

Received: 7 December 2018 Accepted: 25 March 2019

Published online: 28 May 2019

\section{References}

1. Cincura C, Pontes-Neto OM, Neville IS, et al. Validation of the National Institutes of Health Stroke Scale, modified Rankin Scale and Barthel Index in Brazil: the role of cultural adaptation and structured interviewing. Cerebrovasc Dis. 2009;27(2):119-22.

2. Martins SC, Pontes-Neto OM, Alves CV, et al. Past, present, and future of stroke in middle-income countries: the Brazilian experience. Int J Stroke. 2013;8(Suppl. A):106-11.

3. Albers GW, Caplan LR, Easton JD, et al. Transient ischemic attack--proposal for a new definition. N Engl J Med. 2002;347(21):1713-6.

4. Saver UL. Proposal for a universal definition of cerebral infarction. Stroke. 2008:39(11):3110-5.

5. Go AS, Mozaffarian D, Roger VL, et al. Heart disease and stroke statistics 2013 update: a report from the American Heart Association. Circulation. 2013;127(1):e6-e245

6. Pontes-Neto OM, Oliveira-Filho J, Valiente R, et al. Comitê Executivo da Sociedade Brasileira de Doenças Cerebrovasculares; Departamento Científico de Doenças Cerebrovasculares, Academia Brasileira de Neurologia. Brazilian guidelines for the management of intracerebral hemorrhage. Arq Neuropsiquiatr. 2009;67(3B):940-50

7. Pettersen R, Dahl T, Wyller TB. Prediction of long-term functional outcome after stroke rehabilitation. Clin Rehabil. 2002;16(2):149-59.

8. Van de Port IG, Kwakkel G, van Wijk I, et al. Susceptibility to deterioration of mobility long-term after stroke: a prospective cohort study. Stroke. 2006:37(1):167-71.

9. Pound P, Gompertz P, Ebrahim S. A patient centred study of the consequences of stroke. Clin Rehabil. 1998:12(4):338-47.

10. Lord SE, McPherson K, McNaughton HK, et al. Community ambulation after stroke: how important and obtainable is it and what measures appear predictive? Arch Phys Med Rehabil. 2004;85(2):234-9.

11. Perry J, Garrett M, Gronley JK, et al. Classification of walking handicap in the stroke population. Stroke. 1995;26(6):982-9.

12. Gordon NF, Gulanick M, Costa F, et al. Physical activity and exercise recommendations for stroke survivors: an American Heart Association scientific statement from the Council on Clinical Cardiology, Subcommittee on Exercise, Cardiac Rehabilitation, and Prevention; the Council on Cardiovascular Nursing; the Council on Nutrition, Physical Activity, and Metabolism; and the Stroke Council. Circulation. 2004:109(16):2031-41.

13. Lee CD, Folsom AR, Blair SN. Physical activity and stroke risk: a meta-analysis. Stroke. 2003:34(10):2475-81.

14. Carr JH, Mungovan SF, Shepherd RB, et al. Physiotherapy in stroke rehabilitation: Bases for Australian physiotherapists' choice of treatment. Physiother Theory Pract. 1994;10:201-9.

15. Wade D. Rehabilitation therapy after stroke. Lancet. 1999;354(9174):176-7.

16. Roth EJ. Heart disease in patients with stroke: incidence, impact, and implications for rehabilitation. Part I: Classification and prevalence. Arch Phys Med Rehabil. 1993;74(7):752.

17. Roth EJ. Heart disease in patients with stroke. Part II: Impact and implications for rehabilitation. Arch Phys Med Rehabil. 1994;75(1):94.

18. Roth EJ, Heinemann AW, Lovell LL, et al. Impairment and disability: Their relation during stroke rehabilitation. Arch Phys Med Rehabil. 1998;79(3):329.

19. Potempa K, Lopez M, Braun LT, et al. Physiological outcomes of aerobic exercise training in hemiparetic stroke patients. Stroke. 1995;26(1):101

20. Ivey FM, Macko RF, Ryan AS, et al. Cardiovascular health and fitness after stroke. Top Stroke Rehabil. 2005;12(1):1-16.

21. Denadai BS. Consumo máximo de Oxigênio: Fatores determinantes e limitantes. Rev Bras Ativ Fis Saúde. 1995;1:85-94. 
22. Kelly JO, Kilbreath SL, Davis GM, et al. Cardiorespiratory fitness and walking ability in subacute stroke patients. Arch Phys Med Rehabil. 2003;84(12):1780-5.

23. MacKay-Lyons MJ, Makrides L. Cardiovascular stress during a contemporary stroke rehabilitation program: is the intensity adequate to induce a training effect? Arch Phys Med Rehabil. 2002;83(10):1378-83.

24. Eng JJ, Dawson AS, Chu KS. Submaximal exercise in persons with stroke: test-retest reliability and concurrent validity with maximal oxygen consumption. Arch Phys Med Rehabil. 2004;85(1):113-8.

25. Tang A, Sibley KM, Thomas SG, et al. Maximal exercise test results in subacute stroke. Arch Phys Med Rehabil. 2006;87(8):1100-5.

26. Brooks D, Tang A, Sibley KM, et al. Profile of patients at admission into an inpatient stroke rehabilitation programme: cardiorespiratory fitness and functional characteristics. Physiotherapy. 2008;60(2):171-9.

27. Ramas J, Courbon A, Roche F, et al. Effect of training programs and exercise in adult stroke patients: literature review. Ann Readapt Med Phys. 2007;50(6):438-44.

28. Stoller $\mathrm{O}$, de Bruin ED, Knols $\mathrm{RH}$, et al. Effects of cardiovascular exercise early after stroke: systematic review and meta-analysis. BMC Neurol. 2012;12:45.

29. Fletcher GF, Balady G, Froelicher VF, et al. Exercise standards. A statement for healthcare professionals from the American Heart Association. Circulation. 1995:91(2):580-615.

30. De Weerdt W, Selz B, Nuyens G, et al. Time use of stroke patients in an intensive rehabilitation unit: a comparison between a Belgian and a Swiss setting. Disabil Rehabil. 2000;22:181-6.

31. Bruce RA, Kusumi F, Hosmer D. Maximal oxygen intake and nomographic assessment of functional aerobic impairment in cardiovascular disease. Am Heart J. 1973;85(4):546-62.

32. Tang A, Sibley KM, Thomas SG, et al. Effects of an aerobic exercise program on aerobic capacity, spatiotemporal gait parameters, and functional capacity in subacute stroke. Neurorehabil Neural Repair. 2009;23(4):398-406.

33. Enright PL, Sherrill DL. Reference equations for the six-minute walk in healthy adults. Am J Respir Crit Care Med. 1998;158:1384-7.

34. Guyatt GH, Sullivan MJ, Thompson PJ, et al. The 6-minute walk: a new measure of exercise capacity in patients with chronic heart failure. Can Med Assoc J. 1985;132(8):919-23.

35. ATS Statement: Guidelines for the six-minute walk test. This Official Statement of the American Thoracic Society was approved by the ATS Board of Directors. Am J Respir Crit Care Med. 2002;166(1):111-7.

36. Kyle UG, Bosaeus I, Lorenzo AD, et al. Bioelectrical impedance analysis--part I: review of principles and methods. Clin Nutr. 2004;23(5):1226-43.

37. Rodrigues MN, Silva SC, Monteiro WD, et al. Estimativa da gordura corpora através de equipamentos de bioimpedância, dobras cutâneas e pesagem hidrostática. Rev Bras Med Esporte. 2001;7(4):125-31.

38. Nobre F, Coelho EB. Três Décadas de MAPA - Monitorização ambulatorial da pressão arterial de 24 horas: mudanças de paradigmas no diagnóstico e tratamento da hipertensão arterial. Arq Bras Cardiol. 2003;81(4):428-34

39. Revista Brasileira de Hipertensão. VI Diretrizes Brasileiras de Hipertensão. Braz J Hypertens. 2010;17:1.

40. Lang RM, Bierig M, Devereux RB, et al. Recommendations for chamber quantification: a report from the American Society of Echocardiography's Guidelines and Standards Committee and the Chamber Quantification Writing Group, developed in conjunction with the European Association of Echocardiography, a branch of the European Society of Cardiology. J Am Soc Echocardiogr. 2005;18(12):1440-63.

41. Nagueh SF, Appleton CP, Gillebert TC, et al. Recommendations for the evaluation of left ventricular diastolic function by echocardiography. J Am Soc Echocardiogr. 2009;22(2):107-33.

42. Gross JL, Ferreira SRG, Oliveira JE. Glicemia Pós-Prandial. Arq Bras Endocrinol Metab. 2003;6:728-38.

43. DCCT Research Group. Diabetes Control and ComplicationsTrial (DCCT). The effect of intensive treatment of Diabetes on the development and progression of the long-term complications in insulin-dependent diabetes mellitus. N Engl J Med. 1993;329:977-86.

44. Sommer C, White F. Cytokines, chemokines, and pain. Pharmacology of Pain. 1st Ed. Seattle: IASP Press; 2010. p. 279-302

45. Dorman P, Waddell F, Slatterly J, et al. Is the EuroQol a valid measure of health-related quality of life after stroke? Stroke. 1997:28:1876-82.
46. Pinto EB, Maso I, Vilela RN, et al. Validation of the EuroQol quality of life questionnaire on stroke victims. Arq Neuropsiquiatr. 2011;69(2B):320-3.

47. Levy D, Garrison RJ, Savage DD, et al. Prognostic implications of echocardiographically determined left ventricular mass in the Framingham Heart Study. N Engl J Med. 1990;322(22):1561-6.

48. Prescher S, Schoebel C, Koehler K, et al. Prognostic value of serial sixminute walk tests using tele-accelerometry in patients with chronic heart failure: A pre-specified sub-study of the TIM-HF-Trial. Eur J Prev Cardiol. 2016;23(2 suppl):21-6.

\section{Ready to submit your research? Choose BMC and benefit from:}

- fast, convenient online submission

- thorough peer review by experienced researchers in your field

- rapid publication on acceptance

- support for research data, including large and complex data types

- gold Open Access which fosters wider collaboration and increased citations

- maximum visibility for your research: over $100 \mathrm{M}$ website views per year

At $\mathrm{BMC}$, research is always in progress.

Learn more biomedcentral.com/submissions 